\title{
Potensi Limbah Ampas Teh sebagai Alternatif Material Akustik Ramah Lingkungan
}

\author{
U. M. Munifatuzzahroh*, I. Yulianti, Fianti \\ Prodi Pendidikan Fisika, Program Pascasarjana Universitas Negeri Semarang, Indonesia \\ *Email: ukhtiutti@gmail.com
}

Received: June 16 ${ }^{\text {th }}, 2021$. Accepted: July 2nd, 2021. Published: August 29th 2021

\begin{abstract}
Abstrak
Penelitian ini bertujuan untuk mengetahui potensi limbah ampas teh sebagai alternatif material akustik ramah lingkungan. Material akustik dibuat dengan cara mencampur serbuk ampas teh dengan lem fox dan air, dicetak, dan dikeringkan. Material akustik dibuat menjadi enam sampel dengan variasi komposisi ampas teh yang berbeda-beda, yaitu $20 \mathrm{~g}, 40 \mathrm{~g}, 60 \mathrm{~g}, 80 \mathrm{~g}$, $100 \mathrm{~g}$, dan 120 g. Nilai efektifitas reduksi kebisingan dan koefisien serap bunyi, keduanya diperoleh paling optimum pada sampel 6 dengan komposisi $120 \mathrm{~g}$ yaitu sebesar 10,1\% dan 0,07497 $d B$. Nilai keduanya meningkat seiring dengan bertambahnya komposisi ampas teh pada material akustik yang dibuat.
\end{abstract}

\begin{abstract}
The research aims to determine the potential of tea waste as an environmentally friendly alternative acoustic material. The acoustic material is made by mixing tea waste powder with fox glue and water, formed, and dried. The acoustic material was made into six samples with different compositions of tea wastes, that were $20 \mathrm{~g}, 40 \mathrm{~g}, 60 \mathrm{~g}, 80 \mathrm{~g}, 100 \mathrm{~g}$, and $120 \mathrm{~g}$. The value of the effectiveness of noise reduction and the coefficient of sound absorption, both were obtained the most optimum in sample 6 with a composition of $120 \mathrm{~g}$, that were $10.1 \%$ and $0.07497 \mathrm{~dB}$. The value of both increases with the increase of the composition of the tea wastes in the acoustic material.@20121PERJ
\end{abstract}

Keywords: Acoustic material; Tea waste; The effectiveness of noise reduction; The coefficient of sound absorption. 


\section{PENDAHULUAN}

Indonesia pada saat ini telah memasuki era Revolusi Industri 4.0. Salah satu karakteristik Revolusi Industri 4.0 adalah adanya otomatisasi. Otomatisasi memunculkan perubahan secara signifikan di dunia industri, kerja manusia akan tergantikan oleh kerja mesin-mesin (Purwandini \& Irwansyah, 2018). Kerja mesinmesin tersebut sebagian besar berpotensi menimbulkan kebisingan. Kebisingan adalah semua suara yang tidak dikehendaki yang bersumber dari alat-alat proses produksi dan alatalat kerja yang pada tingkat tertentu dapat menimbulkan gangguan pendengaran (Keputusan Menteri Ketenagakerjaan No 51. Tahun 1999). Kebisingan sangat mengganggu dan berdampak buruk bagi kehidupan manusia.

Salah satu alternatif untuk meminimalisir kebisingan adalah dengan pemanfaatan material akustik (ÖZ \& KÖSE, 2020). Material akustik adalah material yang berfungsi untuk menyerap dan meredam suara (Ridwan, Aksar, \& Mahrun, 2016). Material akustik mempunyai peranan penting dalam akustik ruangan. Pemanfaatannya banyak digunakan untuk mengurangi kebisingan pada tempat-tempat seperti studio rekaman, ruang produksi, ruang perkantoran, dan ruang lain yang berpotensi menimbulkan kebisingan.
Material akustik telah banyak dikembangkan, bio-material menjadi salah satu bahan yang baik sebagai alternatif material akustik yang terjangkau dan ramah lingkungan (Zhu, et al., 2014). Hasil penelitian mengenai material akustik berbahan ampas tebu menunjukkan nilai koefisien serap bunyi paling optimum pada sampel dengan tebal 0,26 cm dan kerapatan $0,3 \mathrm{~g} / \mathrm{cm}^{3}$ sebesar 0,89 pada frekuensi $600 \mathrm{~Hz}$ (Puspitarini, S., \& Yulianto, 2014).

Bahan organik lain yaitu bambu berstruktur hollow yang dimanfaatkan sebagai peredam suara alami, menunjukkan nilai koefisien serap bunyi di atas 0,8 dengan susunan aksial (Putra, Khair, \& Nor, 2015). Nilai koefisien serap bunyi yang lebih tinggi ditunjukkan oleh material akustik dari serat tandan kosong kelapa sawit dengan rata-rata sebesar 0,9 pada frekeunsi di atas $1 \mathrm{kHz}$ pada sampel dengan ketebalan $40 \mathrm{~mm}$ dan $50 \mathrm{~mm}$ yang memiliki kerapatan sebesar $292 \mathrm{~kg} / \mathrm{m}^{3}$ (Or, Putra, \& Selamat, 2017). Di sisi lain untuk material akustik dari limbah tongkol jagung mempunyai nilai koefisien serap bunyi rata-rata mencapai 0,215 pada rentang frekuensi 200$1200 \mathrm{~Hz}$ dan nilai tertinggi pada frekuensi $200 \mathrm{~Hz}$ yaitu sebesar 0,273 (Permatasari \& Masturi, 2014). Penelitian lain menyebutkan pesimen dengan komposisi $60 \%$ serbuk dari serat batang pinang raja dan $40 \%$ poliuretan dan gipsum dengan menggunakan serbuk mesh 
32 menghasilkan nilai koefisien absorpsi suara tertinggi yaitu 0,7966 (Warman, Isranuri, \& Wirjosentono, 2016). Berdasarkan hal tersebut, beberapa bio-material memiliki potensi untuk dimanfaatkan sebagai material akustik.

Ampas teh merupakan limbah organik yang pemanfaatnya masih belum maksimal (Wijaya, Martono, \& Riyanto, 2019). Terlebih lagi adanya budaya minum teh didaerah Tegal-Brebes menjadikan limbah ampas teh melimpah dan kurang dimanfaatkan. Limbah ampas teh memiliki kandungan karbon yang cukup tinggi yang berpotensi menjadi karbon aktif. Karbon akif yang dihasilkan dari ampas teh, memenuhi syarat mutu arang aktif (SII No.0258-79) dengan karakteristik kadar air 2,52\%, kadar abu 1,05\%, dan karbon aktif murni 69,5989\% (Fernianti, 2018). Bahan karbon aktif dan komposit nano yang terkandung pada ampas teh ideal untuk digunakan sebagai adsorben bunyi berkinerja tinggi karena spesifkasi luas permukaannya yang sangat tinggi dan volume mikropori yang tinggi (Zhu et al., 2014). Selain itu, kandungan serat pada ampas teh juga memiliki potensi yang cukup besar untuk dijadikan adsorben bunyi. Ampas teh memiliki kandungan holoselulosa sebesar $60,81 \%$, selulosa sebesar 29,42\%, lignin sebesar $36,94 \%$, abu sebesar 4,53\%, dan ekstraktif $15,22 \%$ (Tutuş, Kazaskeroğlu, \& çiçekler, 2015).

\section{METODE}

Alat yang digunakan dalam penelitian ini adalah Sound Level Meter (SLM), Audio Frequency Generator (AFG), speaker, blender, oven, neraca digital, saringan, vaselin dan cetakan. Bahan yang digunakan dalam penelitian ini adalah ampas teh, lem fox dan air.

Ampas teh sisa seduhan teh yang telah dikumpulkan, dikeringkan dengan bantuan sinar matahari. Setelah kering ampas teh dioven selama satu jam. Ampas teh selanjutnya diblender dan disaring. Serbuk ampas teh di campur dengan lem fox dan air untuk dibuat material akustik berupa sampel papan partikel. Setiap sampel divariasikan komposisinya seperti pada Tabel 1. Pengukuran dilakukan pada frekuensi $600 \mathrm{~Hz}$.

Tabel 1. Variasi Komposisi Ampas Teh

\begin{tabular}{ccc}
\hline Sampel & $\begin{array}{c}\text { Ampas teh } \\
(\mathrm{g})\end{array}$ & $\begin{array}{c}\text { Lem fox } \\
\text { cair }(\mathrm{g})\end{array}$ \\
\hline 1 & 20 & 360 \\
2 & 40 & 360 \\
3 & 60 & 360 \\
4 & 80 & 360 \\
5 & 100 & 360 \\
6 & 120 & 360 \\
\hline
\end{tabular}

Skema alat untuk mengukur efektifitas reduksi kebisingan material akustik berupa sampel papan partikel seperti pada Gambar 1 dan Gambar 2. Laptop digunakan untuk mengoperasikan AFG berbasis online. Suara yang telah diatur frekuensinya diteruskan 
melalui speaker. Suara yang di teruskan oleh speaker diukur tingkat kebisingannya menggunakan SLM. SLM yang digunakan berbasis Android. Wadah kotak yang digunakan untuk tempat meletakkan SLM yang dihalangi oleh material akustik terbuat dari kardus yang sisi samping kanan-kirinya terbuka.

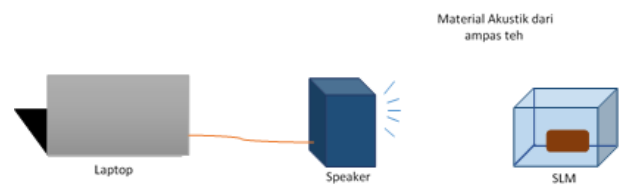

Gambar 1. Skema Alat Pengukuran Efektifitas Reduksi Kebisingan Tanpa Peredam
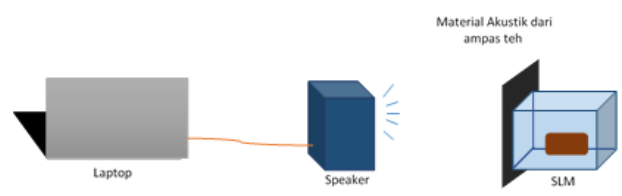

Gambar 2. Skema Alat Pengukuran Efektifitas Reduksi Kebisingan dengan Peredam

Nilai efektifitas reduksi kebisingan dihitung menggunakan Persamaan 1 (Setyo, 1998).

$$
\text { Efektifitas Reduksi }=\frac{K_{T P}-K_{D P}}{K_{T P}} \times 100 \%
$$

Keterangan:

$K_{T P} \quad$ : Tingkat kebisingan tanpa dipasang media peredam (dB)

$K_{D P} \quad$ : Tingkat kebisingan dengan dipasang media peredam $(\mathrm{dB})$

\section{HASIL DAN PEMBAHASAN}

Hasil pengukuran efektivitas reduksi kebisingan material akustik berupa sampel papan partikel dari ampas teh dengan campuran lem fox dan air disajikan pada Tabel 2.

Tabel 2. Efektifitas Reduksi Kebisingan

\begin{tabular}{cc}
\hline Sampel & $\begin{array}{c}\text { Efektifitas Reduksi } \\
(\%)\end{array}$ \\
\hline 1 & 3,9 \\
2 & 4,7 \\
3 & 6,3 \\
4 & 7,1 \\
5 & 8,0 \\
6 & 10,1 \\
\hline
\end{tabular}

Berdasarkan Tabel 2, material akustik berupa sampel papan partikel dari ampas teh dengan campuran lem fox dan air dapat mereduksi kebisingan. Angka efektifitas reduksi meningkat seiring dengan komposisi ampas teh yang juga meningkat. Hasil terbaik ditunjukkan oleh sampel 6, yang artinya material akustik berbahan limbah ampas teh dapat mereduksi kebisingan sebesar 10,1\% dari tingkat kebisingan mula-mula. Angka ini lebih tinggi dibandingkan angka efektivitas reduksi material akustik berupa lapisan styrofoam sebesar 8,32\% (Siti \& Zulfiana, 2018).

Meningkatnya angka efektivitas reduksi kebisingan seiring dengan komposisi ampas teh yang juga meningkat seperti yang ditunjukkan pada Gambar 3, salah satunya dipengaruhi oleh kerapatan sampel (Ika Permatasari \& Masturi, 2014). 
Pada sampel dengan komposisi ampas teh yang rendah, kerapatan permukaan partikel penyusunnya cenderung tertutupi lem fox sehingga menyebabkan bunyi yang datang sedikit diserap oleh pori-pori serbuk ampas teh.

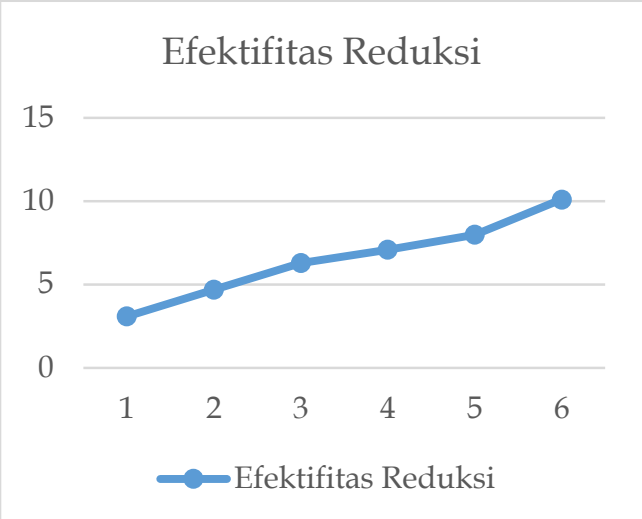

Gambar 3. Grafik Hubungan Komposisi Ampas Teh dengan Angka Efektivitas Reduksi Kebisingan yang Dihasilkan

Sampel dengan komposisi ampas teh yang tinggi memiliki pori-pori yang cukup baik. Bahan berpori dapat mengubah bunyi yang datang menjadi panas, sehingga bunyi dapat diredam dengan baik (Arenas \& Sakagami, 2020). Kemampuan material akustik meredam bunyi akan sangat dipengaruhi oleh penambahan jumlah serat, semakin banyak serat yang diberikan maka semakin baik material akustik tersebut meredam bunyi (Wijaya \& Elvaswer, 2015). Hal ini juga diperkuat oleh penelitian Dewi \& Elvaswer (2015) dan Lindawati (2017) yang menyatakan penyerapan bunyi meningkat dengan meningkatnya komposisi serat dalam material akustik.

Perbedaan komposisi ampas teh yang diberikan pada setiap material akustik berupa sampel papan partikel menghasilkan ketebalan yang berbeda-beda tiap sampelnya. Ketebalan sampel berbanding lurus dengan komposisi ampas teh. Semakin besar komposisi ampas teh semakin tebal pula material akustik berupa sampel papan partikel yang dibuat. Itu artinya semakin tebal sampel semakin besar efektifitas reduksi kebisingan. Ketebalan sampel yang dibuat juga berpengaruh terhadap koefisien serap bunyi seperti yang ditunjukkan pada Tabel 3.

Tabel 3. Koefisien Serap Bunyi

\begin{tabular}{ccc}
\hline Sampel & Tebal $(\mathrm{cm})$ & $\alpha(d B)$ \\
\hline 1 & 0,632 & 0,06466 \\
2 & 0,757 & 0,06481 \\
3 & 0,998 & 0,06573 \\
4 & 1,121 & 0,06594 \\
5 & 1,264 & 0,06604 \\
6 & 1,421 & 0,07497 \\
\hline
\end{tabular}

Koefisein serap bunyi pada tabel 3 menunjukkan bahwa sampel 6 memiliki daya serap bunyi paling baik sebesar 0,07497 $d B$ dibanding sampel yang lain. Hal ini dikarenakan komposisi ampas teh yang ada pada sampel 6 adalah yang terbanyak. Selain itu, sampel 6 juga merupakan sampel dengan ketebalan yang terbesar dibandingkan sampel yang lain. 
Penelitian oleh Lavrentjev (2021) mengungkapkan bahwa terdapat beberapa karakteristik bio-material yang dapat berpotensi menjadi material akustik, yakni material tersebut merupakan material berpori dengan pori-pori berukuran kecil dan struktur pori terbuka, memiliki elastisitas yang tinggi, dan memiliki ketebalan yang cukup besar untuk meredam bunyi pada frekuensi rendah. Komposit dengan tebal yang lebih besar mempunyai ruang yang lebih besar untuk menyerap energi bunyi (Rohim, Fianti, \& Nurbaiti, 2020). Hal itu dikarenakan komposit yang memiliki ketebalan yang lebih besar memiliki pori-pori lebih banyak dan volume lebih besar sehinga penyerapan gelombang bunyi akan lebih efektif (Rezita, Elvaswer, \& Rasyid, 2019). Material akustik akan mempunyai nilai penyerapan bunyi yang lebih tinggi terutama pada frekuensi rendah, apabila ketebalannya ditambah (Khuriati, Komaruddin, \& Nur, 2006). (L.Doelle, 1993) juga mengatakan bahwa efisiensi akustik bahan peredam berpori membaik apabila ketebalannya bertambah pada jangkauan frekuensi rendah.

\section{KESIMPULAN}

Limbah ampas teh potensial untuk dijadikan material akustik karena memiliki nilai efektifitas reduksi kebisingan dan koefisien serap bunyi yang cukup baik. Angka efektifitas reduksi kebisingan dan koefisien serap bunyi, keduanya diperoleh paling optimum pada sampel 6 dengan komposisi $120 \mathrm{~g}$ yaitu sebesar 10,1\% dan 0,07497 $d B$. Angka keduanya meningkat seiring dengan bertambahnya komposisi ampas teh pada material akustik yang dibuat.

\section{DAFTAR PUSTAKA}

Arenas, J. P., \& Sakagami, K. 2020. Sustainable acoustic materials. Sustainability (Switzerland), 12(16): 10-14.

Dewi, A. K., \& Elvaswer. 2015. Material Akustik Serat Pelepah Pisang (Musa Acuminax Balbasiana Calla) sebagai Pengendali Polusi Bunyi. Jurnal Fisika Unand, 4(1): 7882.

Fernianti, D. 2018. Karbonisasi Ampas Teh yang Sudah Diseduh dan Aktifasi Menggunakan Asam Sulfat (H2SOa4). Jurnal Distilasi (Vol. 3).

Permatasari, O. I., \& Masturi. 2014. Penentuan Koefisien Serap Bunyi Papan Partikel Dari Limbah Tongkol Jagung. Jurnal Fisika Unnes, 4(1).

Khuriati, A., Komaruddin, E., \& Nur, M. 2006. Disain Peredam Suara Berbahan Dasar Sabut Kelapa Dan Pengukuran Koefisien Penyerapan Bunyinya. Berkala Fisika, 9(1): 43-53-53.

Doelle, L. 1993. Akustik Lingkungan. Jakarta: Erlangga. 
Lavrentjev, J. 2021. Green ecofriendly acoustic materials. $I O P$ Conference Series: Materials Science and Engineering, 1140(1), 012009.

Lindawati, L. 2017. Karakteristik Akustik Panel Serat Aren Dengan Bahan Perekat Latex. Jurnal Inotera, 2(1), 19-22.

Or, K. H., Putra, A., \& Selamat, M. Z. 2017. Oil palm empty fruit bunch fibres as sustainable acoustic absorber. Applied Acoustics, 119(November), 916.

Öz, H. M., \& Köse, E. 2020. Gürültü Önleyici Akustik Malzemelerin Performans Düzeylerinin İncelenmesi. European Journal of Science and Technology, 18: $1-10$.

Purwandini, D. A., \& Irwansyah. 2018. Komunikasi Korporasi Pada Era Industri 4.0. Jurnal Ilmu Sosial, 17(1): 53-63.

Puspitarini, Y., S., F. M. A., \& Yulianto, A. 2014. Koefisien Serap Bunyi Ampas Tebu sebagai Bahan Peredam Suara. Jurnal Fisika Unnes, 4(2), 96100.

Putra, A., Khair, F. A., \& Nor, M. J. M. 2015. Utilizing HollowStructured Bamboo as Natural Sound Absorber. Archives of Acoustics, 40(4): 601-608.

Rezita, Y., Elvaswer, E., \& Rasyid, R. 2019. Koefisien Absorbsi Bunyi dan Impedansi Akustik dari Ampas Singkong (Manihot esculenta) dengan Menggunakan Metode Tabung.
Jurnal Fisika Unand, 8(2): 146-150.

Ridwan, B., Aksar, P., \& Mahrun. 2016. Analisa mampu redam suara pada material komposit kalsiboard dan gypsum. Ilmiah Mahasiswa Teknik Mesin, 1(1): 39-43.

Rohim, A. M., Fianti, F., \& Nurbaiti, U. 2020. Potensi Sekam Padi dan Jerami sebagai Alternatif Material Akustik. Physics Education Research Journal, 2(1): 35-42.

Siti, H., \& Zulfiana, I. S. 2018. Efektifitas Material Akustik Pengendali Kebisingan pada Ruang Genset di Pusat Perbelanjaan di Gorontalo. JST (Jurnal Sains Terapan), 4(2): 116-121.

Tutuş, A., Kazaskeroğlu, Y., \& çiçekler, M. 2015. Evaluation of tea wastes in usage pulp and paper production.

BioResources, 10(3): 53955406.

Warman, Isranuri, I., \& Wirjosentono, B. 2016. Kajian Karakteristik Absorpsi Suara Material Peredam Suara dari Serat Batang Pinang Raja dengan Menggunakan Poliuretandan Gipsum sebagai Matrik. Jurnal Teknik Dan Teknologi, 11(22): 32-39.

Wijaya, D. R. P., Martono, Y., \& Riyanto, C. A. 2019. Synthesis and Characterization of Nano Activated Carbon Tea Waste (Camellia sinensis L.) Viewed from the Content and Ratio of 
Orthophosphoric Acid. Jurnal Fisika Unand, 4(2):

Indonesian Journal

of 103-105.

Chemical Research, 3(2): 4958.

Wijaya, I., \& Elvaswer. 2015. Pengujian Koefisien Absorbsi Dari Material Akustik Serat Alam Limbah Ampas Tempe Untuk Pengendali Kebisingan.

Zhu, X., Kim, B. J., Wang, Q. W., \& $\mathrm{Wu}, \mathrm{Q} .2014$. Recent advances in the sound insulation properties of bio-based materials. BioResources, 9(1): 1764-1786. 